\title{
Holding Familiar: Planejamento Sucessório para uma Empresa no Segmento Agropecuário
}

\author{
Family Holding: Successory Planning for a Company in the Agribusiness Segment
}

\author{
Jefferson Levy Espindola Dias
}

Universidade Católica Dom Bosco, Programa de Pós-Graduação Stricto Sensu em Desenvolvimento Local. MS, Brasil. E-mail: jdias@jogodenegocios.com.br

\begin{abstract}
Resumo
A questão da cultura do planejamento sucessório se demonstra pouco arraigada no agronegócio Sul-mato-grossense, o que já fez com que muitas famílias vissem patrimônios com dimensões significativas serem particionados ou vendidos em processos de inventário no momento da sucessão. Considerando o fato da urbanização das famílias rurais, de alguns herdeiros não terem aptidão para o agronegócio ou condições de administrá-lo, fica, naturalmente, a preocupação do patriarca com relação à perenidade do negócio e a segurança dos herdeiros. Como solução para essa situação, os produtores rurais podem contar com uma estratégia de gestão corporativa que permite uma administração profissional do negócio, uma sucessão familiar que garanta maior economia, e que dê condições plenas de continuidade da atividade rural, independentemente do falecimento do patriarca e dos interesses dos herdeiros. Trata-se da constituição de uma holding familiar, uma estratégia que permite a construção de estruturas societárias, que separem as áreas produtiva da patrimonial, protegendo, assim, o patrimônio comum dos negócios particulares dos herdeiros. Este artigo analisou as especificidades da implantação de uma holding familiar em uma empresa no segmento agropecuário em Mato Grosso do Sul. A metodologia utilizada passa pela revisão bibliográfica da caracterização da constituição dessas empresas, e os reflexos societários e econômicos para a empresa estudada. Concluiu-se que o projeto é absolutamente viável, tendo o lucro presumido se demonstrado a melhor opção de regime tributário.
\end{abstract}

Palavras-chave: Planejamento Sucessório. Tributário. Holding Familiar. Empresa Rural.

\begin{abstract}
The culture of succession planning is not very well established in Mato Grosso do Sul's agribusiness, which has already caused many families to see assets with significant dimensions being partitioned or sold in inventory processes at the time of succession. Considering the lack of interest or lack of aptitude of heirs for agribusiness, the patriarchs may become concerned with the business perenniality and the safety of the heirs themselves. Nowadays, rural producers can rely on a corporate management strategy that allows for a business professional management, a family succession that guarantees greater economy, and that proposes full conditions to the continuity of rural activity, regardless of the patriarch's death and the interests of the heirs. This is about the creation of a family holding company, a strategy that allows the constitution of a corporate structure that separates the productive area from the patrimonial one, thus protecting the common equity from the heirs' private businesses. This article analyzes the specificities of the implementation of a family holding company in the agricultural sector of Mato Grosso do Sul, Brazil. The methodology used is qualitative because it is the most appropriate to evaluate the changes suggested for management in the corporate, tax and financial areas. The analysis of this management strategy proved to be a much more favorable option than an inventory one. The conclusion was that the project is viable, with presumed profit being the best option of tax regime.
\end{abstract}

Keywords: Succession Planning. Tax Planning. Family Holding. Rural Enterprise.

\section{Introdução}

O Estado de Mato Grosso do Sul tem no agronegócio uma de suas maiores aptidões, já que 17,33\% do seu PIB (produto interno bruto) é proveniente da atividade agropecuária (SEMADE/MS, 2016), questão essa proveniente da posição geográfica, geodésica, das características naturais da região e do domínio tecnológico da produção no cerrado desenvolvido por instituições como a EMBRAPA Cerrados, que conta com uma unidade em Campo Grande - MS. Essas variáveis concorreram de forma intensa e dinâmica para que a agropecuária se desenvolvesse a passos largos no século passado, fazendo com que esse segmento se tornasse cada vez mais importante dentro da economia do Estado.

O segmento do agronegócio sempre recebeu muito incentivo do governo brasileiro, primeiramente, por causa de sua importância para a economia do país e, por outro, pelo alto risco da atividade rural em função da dependência do regime de chuvas e das possibilidades de intempéries no decorrer do projeto. Foi justamente através de uma linha de crédito subsidiada pelo Governo Federal conhecida, nos anos 1970, como Polocentro, que nasceu o projeto de suinocultura que deu início a caminhada do fazendeiro sobre o qual trata este artigo. Naturalmente, que apenas o recurso econômico não é suficiente para que o projeto prospere. A busca por conhecimento e a perseverança para administrar as demandas de um projeto rural também são fundamentais para o seu sucesso, características que este empresário demonstrou ter em sua história.

Será, no entanto, que a geração de seus filhos terá 
competência e vontade para dar continuidade ao projeto encabeçado com tanto esmero pelos seus pais? Certamente, não são muitos aqueles que se preocupam com isso, até porque a maior parte da nova geração acaba seguindo outros rumos profissionais. No entanto, aqueles que dão importância para essa questão, esses necessitarão tomar algumas decisões com relação ao seu patrimônio para não deixar a próxima geração de sua família desprotegida. Haveria uma solução para evitar que o negócio construído pelo patriarca não seja simplesmente vendido pelos filhos e continue a ser uma fonte de receita para eles?

A pesquisa aqui proposta tem, justamente, o propósito de estudar uma solução para este problema que é, hoje, legalmente e economicamente viável, a holding familiar, estratégia de gestão corporativa que existe já há algum tempo, mas que ainda parece não ter se inserido na cultura dos produtores rurais sul-mato-grossenses. Seu objetivo geral, portanto, é demonstrar os benefícios de utilização de uma holding familiar como uma solução para o planejamento sucessório de uma empresa no segmento agropecuário no Estado de Mato Grosso do Sul.

\section{Desenvolvimento}

\subsection{Metodologia}

Com relação aos métodos utilizados, foi realizado um levantamento bibliográfico do contexto legal de uma holding familiar, assim como se utilizou o método descritivo para demonstrar a situação atual da empresa dentro dessa perspectiva. Segundo Roesch (1999), o método escolhido para uma pesquisa deve estar coerente com a forma como o problema foi levantado e, nesse caso, para se definir o melhor regime tributário a ser adotado em uma estrutura corporativa, fez-se necessário levantar sua estrutura de custos, de despesas e de receitas. Em sequência, o levantamento de dados foi realizado por meio de documentos da organização fornecidos pelo empresário.

A análise dos dados foi realizada por meio de uma abordagem qualitativa. Segundo Prodanov e Freitas (2013), a pesquisa qualitativa é um método de interpretação dinâmica, que considera que os fatos não podem ser relevados fora do contexto social, político, econômico, Gil (2002) complementa afirmando que a ênfase maior é colocada na profundidade, o que leva o pesquisador a preferir a utilização de depoimentos e entrevistas com níveis diversos de estruturação. Com relação aos procedimentos, os dados financeiros foram analisados dentro de duas perspectivas tributárias, o lucro presumido e o lucro real, cuja análise buscou demonstrar a melhor opção tributária para a futura empresa. Por outro lado, a questão sucessória foi analisada por uma ótica que apresentou os benefícios da implantação da holding pelo patriarca, enquanto em vida.

\subsection{Contexto Legal de uma Holding Familiar}

De acordo com o que prevê o $\S 3^{\circ}$ do artigo $2^{\circ}$ da Lei $n^{\circ}$ 6.404/76 (BRASIL, 1976) - a Lei das Sociedades Anônimas - o termo holding pode ser conceituado como sendo uma sociedade constituída com o objetivo de manter participações em outras empresas. Apesar dessa definição legal, empresas cujos objetivos mais abrangentes, que tenham como objeto social gerir um patrimônio ou controlar outras empresas são comumente chamadas de holding.

O processo de criação da holding, especialmente, pelo fato de ser em vida, define a sucessão da liderança e do controle patrimonial, o qual passa, efetivamente, para a pessoa jurídica. A liderança pode tanto passar para um determinado herdeiro que tenha maturidade, preparo técnico e valores éticos para ocupar o cargo, quanto para um profissional de mercado com as mesmas características. Portanto, a escolha deixa de ser baseada em questões subjetivas como o nível de ligação entre o pai e um determinado filho, e passa a ser realizada em função das características do profissional, que vai ocupar uma determinada função. O controle patrimonial, portanto, passa para as mãos de uma empresa, a qual tem regras mais rígidas no que tange a gestão do ativo fixo que foi transferido para essa, como a obrigação dos gestores de apresentar relatórios de resultado aos sócios em períodos prédeterminados em contrato. Caso este profissional não cumpra com as obrigações do cargo, o mesmo pode ser substituído (SILVA; ROSSI, 2017).

Doações com usufruto devem conter algumas cláusulas importantes que concorrem para a efetiva proteção do patrimônio. O usufruto vitalício dos patriarcas, em si, está em consonância com o artigo 1.394 do Código Civil (BRASIL, 2002), que menciona que "o usufrutuário tem direito à posse, uso, administração e percepção dos frutos" da empresa. A cláusula da inalienabilidade, por sua vez, está prevista no artigo 1.911 do Código Civil, e implica na impenhorabilidade dos bens. Sua previsão vem dar efetividade à cláusula de inalienabilidade, uma vez que se os bens fossem penhorados, estes seriam, por conseguinte, expropriados do seu beneficiário. Outra cláusula importante é a incomunicabilidade, prevista nos artigos 1.668, 1.669 e 1.911 do Código Civil. Essas cláusulas têm como função não permitir a comunicabilidade dos direitos dos bens doados a terceiros, especificamente ao cônjuge de seu herdeiro.

De forma análoga, mas em sentido contrário ao que foi supracitado, os herdeiros que tenham bens não terão os mesmos diretamente envolvidos na atividade empresarial da holding, o que reduz os riscos atinentes à afetação dos bens privados (SILVA; ROSSI, 2017).

\subsubsection{Espécies de Holding}

Existem duas espécies de holding: a holding pura e a holding mista. Segundo Silva e Rossi (2017, p.21), a holding pura "tem como objetivo social e exclusivo a participação 
no capital de outras sociedades, isto é, uma empresa que tem como atividade única manter quotas ou ações de outras companhias". A holding mista, por sua vez, tem como objeto social não apenas a participação em outras empresas, mas também prevê sobre o exercício de exploração de alguma atividade econômica.

\subsubsection{Tipos Societários de uma Holding}

De acordo com a legislação vigente, existem três tipos societários que podem ser utilizados no caso da holding: a EIRELI (Empresa Individual com Responsabilidade Limitada), a Sociedade por Responsabilidade Limitada e a Sociedade Anônima.

A EIRELI - Empresa Individual com Responsabilidade Limitada - que foi instituída e inserida no cenário empresarial, pela Lei $\mathrm{n}^{\circ} 12.441 / 11$, é um tipo societário, como o próprio nome diz, constituída por um único sócio. Foi criada para regulamentar a constituição de uma empresa com uma única pessoa titular da totalidade do capital social, o qual não pode ser inferior a 100 (cem) vezes o salário-mínimo vigente no país. Uma EIRELI como uma holding, no entanto, causa divergências entre os autores. Mamede e Mamede (2017, p.124) afirmam que não há problema, uma vez que:

Embora a Lei 12.441/11 seja confusa em seu conteúdo, diversos de seus termos apontam para essa solução, a principiar pela referência a capital social (artigo 908-A, caput, do Código Civil) que é próprio das sociedades, e não a capital registrado, que é expressão mais ampla e, assim, adequada para uma pessoa jurídica sui generis, como querem alguns. Não é só; o $\S 3^{\circ}$ do mesmo artigo [...] reconhece que a eireli pode resultar da concentração de quotas de uma sociedade limitada nas mãos de um único sócio. Por fim, o $\S 6^{\circ}$, segundo o qual se aplicam à empresa individual de responsabilidade limitada, no que couber, as regras previstas para as sociedades limitadas.

A Sociedade por Responsabilidade Limitada é um tipo de sociedade, que deve ser constituída por mais de uma pessoa, seu Capital deve ser dividido em quotas, cada sócio deve subscrever uma determinada quantidade dessas cotas, e a responsabilidade de cada sócio deve ser restrita ao valor das suas quotas. No entanto, caso um sócio subscreva, mas não integralize suas quotas, todos os sócios devem responder solidariamente pela integralização do capital social, se tornando, assim, responsáveis pela importância faltante perante a sociedade e terceiros, conforme rege o artigo 1.052 do Código Civil (SILVA; ROSSI, 2017). Além disso, uma das cláusulas do contrato social de uma sociedade limitada deve indicar a responsabilidade de administrador para um ou mais sócios.

Sociedades empresariais podem se distinguir entre sociedade de pessoas e sociedade de capital. No caso das sociedades limitadas, o tipo preponderante é a sociedade de pessoas na qual se sobressaem os atributos de cada sócio, as afinidades pessoais e a mútua confiança das pessoas que a compõe. De acordo com Silva e Rossi (2017, p.32), com esse conceito surge a "affectio societatis, que se define como a vontade de união entre os sócios para constituir e manter uma sociedade, obedecendo a seu objeto social e sempre visando ao sucesso". Trata-se do fato dos sócios compartilharem interesses idênticos e colaborarem, conscientemente, com o atendimento do objeto social da sociedade. Todos os atos desse tipo societário devem ser arquivados na Junta Comercial e, uma vez integralizado todo o capital, nenhum dos sócios pode ser mais chamado a responder pelas dívidas da sociedade com seus bens particulares, uma vez que a responsabilidade se torna limitada ao capital integralizado.

A Sociedade Anônima, que é disciplinada pela Lei $\mathrm{n}^{\circ}$. 6.404/1976 (BRASIL, 1976), tem seu capital dividido em ações de livre negociação, pode ser fechada ou aberta e a responsabilidade dos acionistas é restrita ao valor das ações em sua propriedade. Conforme observado supra, sociedades empresariais podem se distinguir entre sociedade de pessoas e sociedade de capital. No caso das sociedades anônimas, o tipo preponderante é a sociedade de capital, uma vez que um leque maior de investidores podem adquirir lotes de ações da empresa, sem ter qualquer participação na operação da mesma. Esse tipo societário é constituído com base em um estatuto social, o qual deve ser registrado na Junta Comercial de sua sede.

Esse tipo de sociedade deve possuir três órgãos: Conselho Fiscal, Assembleia Geral e Diretoria. São nas assembleias gerais que as decisões que vão decidir os rumos de atuação da empresa são tomadas. A Assembleia Geral tem poderes para decidir todos os negócios relativos ao objeto da companhia e tomar as resoluções que julgar convenientes para sua defesa e desenvolvimento. Sua operação é normalmente realizada por profissionais de mercado, os quais assumem como diretores e tem a responsabilidade de fazê-lo com a devida eficácia e ética. Os custos de administração são, naturalmente, mais elevados, mas também o é sua capacidade de geração de caixa.

\subsubsection{Tipos de Sucessão}

O planejamento sucessório é uma das bases, que envolve a constituição de uma holding familiar, pois deve ser realizado de maneira antecipada para evitar que a falta do patriarca desestabilize o negócio da família. Ele permite que os pais protejam os bens que serão repassados aos filhos. A sucessão de bens, por sua vez, pode ser feita através de inventário, sucessão testamentária, e antecipação da legítima.

Transferências de patrimônio podem causar muita discussão entre herdeiros. O processo de inventário, que faz a partilha dos bens, pode se arrastar por anos, caso os herdeiros não se entendam acerca dessa divisão. Além disso, trata-se de uma das soluções mais custosas, visto pagar: os honorários advocatícios, que variam de $2 \%$ a $10 \%$ do patrimônio; o ITCMD (Imposto sobre Transmissão Causa Mortis e Doações) que representa 4\% do patrimônio; as custas processuais que variam de 10 a 3.000 UFERMS (Unidade Fiscal Estadual de Referência de Mato Grosso do Sul) que, em setembro de 2017, 
estava em R $\$ 23,93$; e, por fim, os emolumentos cartoriais. Como o não pagamento do ITCMD pode interromper o processo, caso os herdeiros não tenham condições financeiras, muitas vezes, eles acabam tendo que se desfazer de um bem para cobrir as despesas da ação.

O falecimento tem como consequência jurídica a sucessão de bens, conforme se pode verificar no artigo 1.822 do Código Civil. Existem duas formas de sucessão: legítima e testamentária. Em ambas devem ser respeitados os direitos hereditários, inclusive os relacionados ao cônjuge, o qual, no atual Código Civil, artigo 1.845, foi alçado à condição de herdeiro necessário, junto com ascendentes e descendentes. A legítima, portanto, refere-se à metade dos bens da herança que, de acordo com o artigo 1.846 do Código Civil, pertencem aos herdeiros necessários. Essa metade é protegida por lei e não pode nem ser objeto de testamento e nem de doação. A outra metade é considerada a parte disponível, podendo o proprietário dispor dessa como quiser (SILVA, 2017).

Dentro da estratégia de constituição da holding familiar, aqui exposta, está a doação das quotas da empresa criada para os herdeiros. O objetivo é evitar que a divisão dos bens familiares entre os herdeiros ocorra apenas no momento do falecimento dos patriarcas, com todos os inconvenientes deste fato e, especialmente, no caso de um eventual processo judicial de inventário. De acordo com o artigo 538 do Código Civil, "considera-se doação o contrato em que uma pessoa, por liberalidade, transfere do seu patrimônio bens ou vantagens para o de outra". Como forma de garantir a subsistência do doador, o artigo 548 reza que a doação pode ser considerada nula, caso ele faça a doação de todos os seus bens, evitando, assim, sua insolvência. A doação também não pode atingir a parte legítima de bens do doador. A doação que exceda a metade considerada disponível é chamada de "doação inoficiosa", sendo considerada nula, conforme o artigo 549 do Código Civil.

Em função dessas características, surge o que é denominado antecipação da legítima, que denota a disposição prévia dos bens, que seriam transferidos no momento da sucessão, ou seja, "a doação de ascendentes para descendentes, ou de um cônjuge a outro, importa adiantamento do que lhes cabe por herança", conforme o artigo 544 do Código Civil (BRASIL, 2002).

\subsubsection{Planejamento Tributário}

A gestão financeira é responsável pela gestão dos fluxos de recursos financeiros, e tem a responsabilidade de captar os recursos necessários para as atividades da empresa (decisões de financiamento) e aplicar os recursos financeiros gerados pelo negócio, de modo a atingir os objetivos organizacionais (decisões de investimento). Entre as funções da gestão financeira se encontram: o planejamento financeiro, o controle financeiro, e a administração de ativos e passivos. O planejamento financeiro tem por objetivo definir as metas de rentabilidade dos investimentos, procura mensurar necessidades de expansão e monitora os resultados para identificar ajustes necessários. É justamente no planejamento financeiro que se insere o planejamento tributário (GITMAN, 2002).

O planejamento tributário consiste no estudo dos tipos societários, regimes tributários e delimitações operacionais das empresas com o fim de busca pela elisão fiscal, ou seja, de maneiras legais de redução da carga de impostos e eficácia administrativo-financeira. Pelo nível de abrangência deste estudo, o qual deverá nortear a gestão de custos, a formação do preço de venda e a eficácia alcançada com o investimento em ativos, pode-se dizer que este estudo assume os contornos de um planejamento estratégico orçamentário, que tem como objetivo melhorar a eficiência de aplicação dos recursos e produzir melhores resultados para a empresa (PADOVEZE, 2012).

\subsubsection{Regimes Tributários}

Entre as opções de regimes tributários disponibilizados pela legislação, no caso da empresa em pauta, têm-se os regimes do lucro real, do lucro presumido e do Simples Nacional. Por se tratar de uma empresa que fatura acima de $\mathrm{R} \$ 12.000 .000,00$ por ano, o Simples Nacional não se enquadra, pois seu limite de faturamento é de R \$3.600.000,00. Portanto, seguem abaixo detalhes sobre os regimes do lucro presumido e do lucro real.

No caso do lucro real, o fato jurídico que corresponde à aquisição de disponibilidade econômica de receita será a existência de acréscimo patrimonial, dimensionado pelo lucro do exercício, ou seja, a obtenção de resultados positivos (lucros) em suas operações.

De acordo com a Lei $n^{\circ}$ 9.430/1996 (BRASIL, 1996), além do imposto de renda da pessoa jurídica, também incide sobre o lucro das empresas a Contribuição Social sobre o Lucro Líquido, sendo este último imposto recolhido para o financiamento da seguridade social.

O lucro real é a única metodologia que calcula o lucro se baseando no lucro contábil, que será a base do IRPJ (Imposto de Renda Pessoa Jurídica) e da CSLL (Contribuição Social sobre o Lucro). As demais presumem ou arbitram o lucro, de acordo com regras preestabelecidas pela legislação. O simples nacional, por sua vez, calcula os impostos baseando-se no faturamento.

No caso do lucro real, em termos de planejamento tributário, deve-se ficar atento às desvantagens da opção pelo lucro real trimestral, pois:

O lucro apurado em um trimestre no ano calendário não pode absorver prejuízo fiscal que venha a ocorrer em trimestres subsequentes.

O prejuízo fiscal ou a base negativa da CSLL de um trimestre só pode reduzir, no máximo, em 30\% o lucro real, ou a base de cálculo positiva da CSLL, dos trimestres seguintes.

O limite trimestral - R\$ 60 mil - para não incidência do adicional de $10 \%$ de IR é não cumulativo.

O lucro contábil pode ser ajustado através de adições, de 
exclusões e de compensações que devem ser registradas e apresentadas na respectiva Escrituração Contábil Fiscal (ECF). As alíquotas aplicadas para o cálculo dos impostos sobre o lucro variam em função da atividade da empresa (comércio ou serviço). Caso a empresa tenha receitas provenientes de diferentes atividades, as receitas deverão ser segregadas e os impostos (IRPJ e CSLL) calculados sobre o montante de cada uma das receitas decorrentes das atividades realizadas.

No lucro presumido, por sua vez, apenas o ICMS é não cumulativo, para o qual se deve fazer a compensação entre o crédito na entrada e o débito na saída. Prejuízos fiscais não podem ser compensados visto que o imposto é calculado mediante uma presunção do lucro sobre o faturamento, não levando em consideração a possibilidade de resultado negativo.

Uma vez calculado o lucro, o qual é presumido através de alíquotas definidas em lei em função do segmento de mercado, este se torna a base de cálculo para o IRPJ e da CSLL. Para se calcular o imposto, as alíquotas são as mesmas do lucro real. O que muda é o limite - R \$20 mil por mês para não incidência do adicional de $10 \%$ do imposto de renda sobre a parcela do lucro presumido, que exceder ao valor da multiplicação de $\mathrm{R} \$ 20.000,00$ (vinte mil reais) pelo número de meses do respectivo cálculo (BRASIL, 1996).

\subsection{Planejamento Tributário no Contexto de uma Empresa Familiar Rural}

O objeto de estudo deste artigo é uma empresa rural, que nasceu na década de 1970 . O primeiro projeto rural desenvolvido pelo patriarca, à época com quase 40 anos, foi uma suinocultura que pode ser viabilizada através do programa Polo Centro, que foi um dos programas criados pelo Governo Federal, com grande raio de ação, implementado entre 1975 e 1984 para promover o crescimento econômico na região Centro-oeste. Desde a década de 1960 , a produção agrícola vinha ganhando impulso por três fatores: pelo crescimento do mercado interno de alimentos e de matérias-primas industriais, pela política de substituição energética de derivados de petróleo por biomassa, a partir de 1975 (Programa Nacional do Álcool), e pelo crescimento das exportações agrícolas que voltaram a crescer, principalmente, na década de 1970. Segundo Kageyama (1986, p.38 apud JESUS, 1988, p.16), naquele período, o país assistia o aprofundamento da integração da agricultura com os setores industriais, e sua modernização em direção a um setor agropecuário especializado e altamente mercantilizado. Acompanhando esta maré de investimentos no setor agropecuário, o Polocentro foi oferecido aos empresários com taxas subsidiadas pelo Governo Federal (abaixo de 5\% ao ano), o que tornou o programa extremamente atrativo e viabilizou o investimento na granja de suínos.

Naquele período, a demanda era maior que a oferta, e ainda havia poucos produtores no país, o que fez com que tudo que se produzisse, fosse vendido. Dentro de uma realidade econômica, extremamente favorável, não demorou muito para que a granja fosse ampliada, o que aconteceu não uma, mas várias vezes, fazendo a granja crescer de 360 matrizes para as atuais 2.040 matrizes. Alguns anos após a construção da granja surgiu a primeira oportunidade de comprar uma fazenda e iniciar uma criação de gado. O gado cresceu rapidamente embalado por um Brasil, que deixava o período inflacionário para trás e retomava o crescimento econômico após o Plano Real, somando-se a isso o aumento da renda média do brasileiro que passou a consumir mais carne. Hoje, este empresário conta com duas fazendas de gado e a suinocultura. Este trabalho está focado, somente, no projeto da suinocultura.

\subsubsection{Opções Tributárias para Constituição da Holding Familiar}

Pelo fato da nova empresa se tratar de uma pessoa jurídica com faturamento anual por volta dos $\mathrm{R} \$ 12.000 .000,00$ (doze milhões de reais), de acordo com a Lei Geral das Micro e Pequenas Empresas, essa se enquadra como uma empresa de médio porte, não podendo optar, dessa forma, pelo Simples Nacional que se limita a empresas de pequeno porte com até $\mathrm{R} \$ 4.800 .000,00$ de faturamento anual. Sendo assim, essa empresa poderá optar pelos regimes tributários do lucro real e do lucro presumido. Portanto, o estudo que se segue tem por objetivo demonstrar as estimativas de resultado para essas duas opções.

O Quadro 1 demonstra o resultado líquido estimado para o caso da empresa optar pelo lucro real.

Quadro 1 - Estimativa do Resultado pelo Lucro Real

\begin{tabular}{|l|c|r|}
\hline \multicolumn{3}{|c|}{ Regime Tributário - Lucro Real } \\
\hline Receita Bruta & & $\mathbf{1 2 . 0 0 0 . 0 0 0 , 0 0}$ \\
\hline Deduções da Receita & soma & $3.150 .000,00$ \\
\hline ICMS & $17,00 \%$ & $2.040 .000,00$ \\
\hline PIS & $1,65 \%$ & $198.000,00$ \\
\hline COFINS & $7,60 \%$ & $912.000,00$ \\
\hline Comissões & & - \\
\hline Receita Líquida & & $\mathbf{8 . 8 5 0 . 0 0 0 , 0 0}$ \\
\hline Custo dos Produtos Vendidos & $66,4 \%$ & $7.000 .350,02$ \\
\hline Crédito dos impostos & soma & $1.697 .584,88$ \\
\hline ICMS & $15,0 \%$ & $1.050 .052,50$ \\
\hline PIS & $1,65 \%$ & $115.505,78$ \\
\hline COFINS & $7,60 \%$ & $532.026,60$ \\
\hline Custo dos Produtos & Liquido & $5.302 .765,14$ \\
\hline Lucro Bruto & & $\mathbf{3 . 5 4 7 . 2 3 4 , 8 6}$ \\
\hline Despesas operacionais & soma & $1.724 .333,94$ \\
\hline LAIR & & $\mathbf{1 . 8 2 2 . 9 0 0 , 9 2}$ \\
\hline IRPJ & $15 \%$ & $273.435,14$ \\
\hline IRPJ - Adicional & $10 \%$ & $176.290,09$ \\
\hline CSLL & $9 \%$ & $164.061,08$ \\
\hline Lucro Líquido & & $\mathbf{1 . 2 0 9 . 1 1 4 , 6 1}$ \\
\hline Impostos & & $\mathbf{2 . 0 6 6 . 2 0 1 , 4 3}$ \\
\hline Fo D
\end{tabular}


No caso do lucro real, os impostos são não cumulativos e, portanto, ocorre a compensação dos impostos ICMS, PIS e COFINS no que tange aos custos do produto vendido (CPV), nos quais se inserem os insumos de nutrição, de inseminação, de sanidade e de reposição do plantel. Como cerca de $10 \%$ desses produtos vem de fora do Estado, utilizou-se a alíquota aproximada de $15 \%$ para o crédito de ICMS.

O Quadro 2 demonstra o resultado líquido estimado para o caso da empresa optar pelo regime tributário do lucro real.

Quadro 2 - Estimativa de Resultado pelo Lucro Presumido

\begin{tabular}{|c|c|c|}
\hline \multicolumn{3}{|c|}{ Regime Tributário - Lucro Presumido } \\
\hline Receita Bruta & & $12.000 .000,00$ \\
\hline Deduções da Receita & Soma & $2.238 .000,00$ \\
\hline ICMS & $15,00 \%$ & $1.800 .000,00$ \\
\hline PIS & $0,65 \%$ & $78.000,00$ \\
\hline COFINS & $3,0 \%$ & $360.000,00$ \\
\hline Comissões & & 0,00 \\
\hline Receita Líquida & & $9.762 .000,00$ \\
\hline Custo dos Produtos Vendidos & $66,4 \%$ & $7.000 .350,02$ \\
\hline ICMS (crédito) & $15,0 \%$ & $1.050 .052,50$ \\
\hline Produtos & Liquido & $5.950 .297,52$ \\
\hline Lucro Bruto & & $3.811 .702,48$ \\
\hline Despesas operacionais & & $1.724 .333,94$ \\
\hline LAIR & & $2.087 .368,54$ \\
\hline \multicolumn{3}{|l|}{ Cálculo do IRPJ } \\
\hline Base de cálculo ( $8 \%$ x rec. bruta) & $8 \%$ & $960.000,00$ \\
\hline IRPJ & $15 \%$ & $144.000,00$ \\
\hline $\begin{array}{l}\text { IRPJ adicional (descto } \$ 240 \mathrm{mil} \\
\text { base) }\end{array}$ & $10 \%$ & $72.000,00$ \\
\hline \multicolumn{3}{|l|}{ Cálculo do CSLL } \\
\hline Base de cálculo ( $12 \%$ x rec. bruta) & $12 \%$ & $1.440 .000,00$ \\
\hline CSLL & $9 \%$ & $129.600,00$ \\
\hline Lucro Líquido & & $1.741 .768,54$ \\
\hline Impostos & & $1.533 .547,50$ \\
\hline
\end{tabular}

Fonte: Dados da pesquisa

No caso do lucro presumido, apenas o ICMS é não cumulativo com o qual ocorre a compensação entre os impostos de entrada e de saída do imposto estadual. Os impostos federais (PIS e COFINS) são calculados apenas com base no faturamento.

O Quadro 2, por sua vez, demonstra o resultado líquido estimado para o caso da empresa optar pelo regime tributário do lucro presumido. Pode-se observar que o lucro real apresenta uma carga tributária $\mathrm{R} \$ 292.653,94$ (duzentos e noventa e dois mil, seiscentos e cinquenta e três reais) maior que o lucro presumido. Consequentemente, o lucro líquido neste regime foi maior que o lucro alcançado com o lucro real.

Embora o lucro presumido tenha se demonstrado a melhor opção neste estudo comparativo, o setor de suinocultura já passou por períodos de prejuízo. O lucro presumido não conta com a possibilidade da compensação de prejuízos fiscais. Para a atividade rural, por outro lado, o lucro real não está sujeito ao limite de $30 \%$ (trinta por cento) supracitado, ou seja, pode ser integralmente compensado com o resultado dessa mesma atividade, apurado em períodos de apuração subsequentes, observando-se que o lucro seja o apurado no Livro de Apuração do Lucro Real (LALUR), conforme artigo 512 do RIR/99, hoje substituído pelo e-Lalur, versão eletrônica do livro, instituído pela Instrução Normativa RFB 989/2009.

\subsubsection{Comparação entre a Holding Familiar e a Instauração de um Inventário}

A constituição de uma holding familiar, como se pode observar, resolve a questão da administração da empresa antecipadamente ao evento da falta do patriarca, ou seja, a sucessão do patrimônio e da gestão da empresa já foram decididas em vida sob a tutela do empresário(a). A transição e o novo modelo de gestão podem ser testados de tal forma a permitir uma sucessão tranquila. Portanto, não há interrupção da gestão dos bens e negócios da família.

No caso de um processo inventarial ou testamentário, a morte do administrador surpreende a família e a empresa, e sua gestão se tornará mais um assunto dentro do inventário. Caso os herdeiros não consigam uma solução consensual, o processo de partilha dos bens pode ser marcado por disputas, o que pode tornar o inventário litigioso, e prejudicar a administração da empresa. Mesmo após o encerramento da disputa pelos bens, ainda podem surgir disputas pelo controle da empresa.

No caso de implementação da holding, no momento que o patriarca venha a faltar, os bens já não estarão mais em seu nome, não havendo, portanto, bens a dividir. Caso contrário, a família terá que arcar com as custas de partilha e de transmissão dos bens, o que envolve os honorários advocatícios (de $2 \%$ a $10 \%$ do patrimônio), o ITCMD ( $4 \%$ do patrimônio), as custas processuais (3.000 UFERMS - R \$71.790,00 em Set/2017), e os emolumentos cartoriais (até $\mathrm{R} \$ 6.500,00$ por imóvel). Como o não pagamento do ITCMD pode interromper o processo, pode ser que a família tenha que se desfazer de algum bem para cobrir as despesas da ação.

\subsubsection{Benefícios do Planejamento Sucessório para a Perenidade da Empresa Rural}

A constituição de uma holding familiar traz várias vantagens para seus sócios. $\mathrm{O}$ fato dos bens estarem em nome de uma pessoa jurídica tem maior controle operacional dos bens. Não são pessoas físicas, muitas vezes despreparadas, que deliberam sobre o sistema produtivo e o resultado advindo do investimento realizado na estrutura patrimonial por esse administrador, sendo gestores profissionais para a holding, dos quais, inclusive, pode participar um sócio que tenha formação e tenha se preparado para a função. Portanto, o processo de tomada de decisão passa por um crivo técnico de pessoas mais maduras para a gestão do patrimônio.

A ideia é que a empresa seja administrada por profissionais que, realmente, tenham conhecimento, formação e maturidade para gerir o negócio. Ao se comparar a possibilidade de uma gestão profissional, baseada em uma relação comercial 
definida em contrato, com a gestão em uma estrutura que não seja profissionalizada, observa-se que a atuação das partes envolvidas deixa de ser baseada nas regras preestabelecidas em contrato, e passa para níveis subjetivos baseados na relação familiar entre as partes, a qual é, normalmente, baseada em acordos subliminares e na procrastinação, dois costumes que não coadunam com a performance exigida de uma gestão corporativa. Para fins de análise, não adianta, por exemplo, tomar-se uma decisão de correção de rumo no mês de maio baseando-se nos resultados referentes ao mês de fevereiro. Fechamento de resultado financeiro deve ser realizado, no mínimo, mensalmente, resultados operacionais e comerciais, semanalmente, e decisões corretivas devem ser tomadas constantemente. Para que isso ocorra, de forma adequada, não há espaço para protelações e desculpas, o que pode facilmente ser aceito em uma estrutura puramente familiar.

Viscardi (2017) comenta que uma holding familiar pode facilitar a transição da gestão da empresa entre as diferentes gerações, que venham a participar do processo. Além disso, "há benefícios na redução dos ônus tributários (rendimentos de aluguéis e ganho de capital), liberdade para transacionar imóveis em geral (compra, venda, incorporação, permutas, etc.) e o principal que é a preservação dos bens adquiridos ao longo de uma vida, sem que todos vão a inventário após a falta do patriarca" (TEIXEIRA JUNIOR, 2017).

\section{Conclusão}

São nítidos os benefícios de utilização de uma holding familiar como solução para o planejamento sucessório, começando do momento em que o patriarca venha a faltar, com uma redução significativa das custas inventariais que são mínimas, uma vez comparadas a um inventário de pessoa física. Com a questão da partilha de bens e da gestão da empresa resolvidas, sobram poucas razões para disputas e desavenças entre os herdeiros. A tendência, portanto, é que a família possa se concentrar na administração das questões sentimentais, uma vez que há profissionais trabalhando para manter a atividade produtiva em andamento.

A empresa segue seu caminho contando com profissionais em sua gestão, os herdeiros e sócios da empresa continuam recebendo sua distribuição de lucros, os herdeiros, que não quiserem atuar na empresa, têm total liberdade para atuar na profissão que quiserem, tendo, de qualquer forma, um suporte financeiro no qual se apoiar. A atividade rural permanece sendo um patrimônio da família, e os herdeiros seguem protegidos pela gestão de pessoas capazes de garantir a longevidade desse patrimônio.

\section{Referências}

BRASIL. Lei 6.404 de 1976. Lei das Sociedades Anônimas. Brasília-DF, 1976.

BRASIL. Lei 10.406 de 10 de Janeiro de 2002. Código Civil. Brasília-DF, 2002.

BRASIL. Lei 9.430 de 27 de Dezembro de 1996. Legislação Tributária Federal. Brasília-DF, 1996.

GIL, A.C. Como elaborar projetos de pesquisa. São Paulo: Atlas, 2002.

GITMAN, L.J. Princípios de administração financeira. São Paulo: Harbra, 2002.

JESUS, L.C.F. A ocupação dos Cerrados: o Polocentro e seus impactos em Minas Gerais. Campinas: Uncamp, 1988.

KAGEYAMA, Â. et al. A dinâmica da agricultura brasileira 1965/1985. Campinas: UNICAMP, 1987.

MAMEDE, G.; MAMEDE, E.C. Holding familiar e suas vantagens. São Paulo: Atlas, 2017.

PADOVEZE, C.L. Controladoria estratégica e operacional: conceitos, estrutura, aplicação. São Paulo: Cengage Learning, 2012.

PRODANOV, C.C.; FREITAS, E.C. Metodologia do trabalho cientifico. Novo Hamburgo: Freevale, 2013.

ROESCH, S.M.A. Projetos de estágio e de pesquisa em administração. São Paulo: Atlas, 1999.

SILVA, F.P. Holding familiar: visão jurídica do planejamento familiar, sucessório e tributário. São Paulo: Trevisan, 2017.

TEIXEIRA JUNIOR, F. Holding familiar para produtores rurais. 2017. Disponível em: http://holdingfamiliar.net/ holdingfamiliarparaprodutoresrurais/. Acesso em: 5 abr, 2018.

VISCARDI, D. Holding familiar: planejamento sucessório para produtores rurais. 2017. Disponível em: https://www.jurisway. org.br/v2/dhall.asp?id_dh=13901. Acesso em: 4 abr. 2018. 